\title{
IMPLEMENTASI MODEL STOKASTIK PADA PERMASALAHAN OPTIMASI PERSEDIAAN KELAPA PADA TINGKAT DISTRIBUTOR
}

\author{
Novi Rustiana Dewi ${ }^{1 \S}$, Eka Susanti ${ }^{2}$ Bambang Suprihatin ${ }^{3}$, Agustina Bidarti ${ }^{4}$, \\ Sinta Elpatrika Abelia ${ }^{5}$, Neysa Adiratna Agmi Masyithah ${ }^{6}$

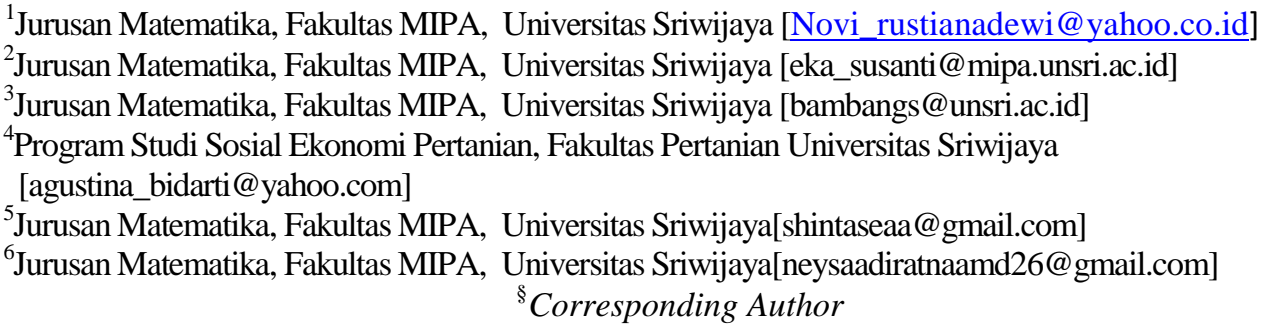

ABSTRACT

In the inventory system is given operational policies relating to product inventory control, such as how much is ordered, when to order with the aim of minimizing storage and ordering costs. Customer demand and lead time affect the inventory system. This study aims to determine the densitas distribution of demand data, total inventory costs and optimal coconut supply for the two order periods using the stochastic inventory model. Stochastic inventory models can be used if there is variable uncertainty. This paper discusses the optimization of coconut inventories using a stochastic model with uncertainty about demand and lead time. It is known that demand data is uniformly distributed, based on the realization value of random variable requests can be formed in 49 scenarios. Obtained an optimal total inventory cost for the two planning periods is Rp. 45,672,910, optimal supply for period one was 26031 coconuts. Inventory levels in two period for any scenarios are 5814; 7026; 26031; 18703; 7599; 6033; 18608; 11280; 176; 16603; 17815; 36820; 29492; 18388; $16822 ; 1916 ; 3128 ; 22133 ; 4805 ; 3701 ; 2135 ; 4814 ; 24401 ; 25613 ; 44618 ; 37290 ; 26186 ; 24620$; $12086 ; 4758$.

Keywords: Stochastic model, Optimization, Inventory

\section{PENDAHULUAN}

Pada sistem persediaan atau inventori diberikan kebijakan operasional yang berkaitan dengan pengendalian penyimpanan produk, seperti berapa banyak yang dipesan, kapan waktu pemesanan dengan tujuan meminimumkan biaya penyimpanan dan pemesanan. Penelitian terkait inventori dan metode penyelesaian telah banyak dikembangkan serta diaplikasikan di berbagai bidang. Permasalahan inventori dan supply chain untuk menentukan lokasi optimal, rute optimal pada kegiatan distribusi dibahas oleh (Zheng, Yin, \& Zhang, 2019). Pada (Sanni \& Neill, 2019) dibahas permasalahan optimasi inventori dengan variasi sistem pembayaran. (Cárdenas-barrón, Shaikh, Tiwari, \& Treviñogarza, 2018) membahas permasalahan inventori menggunakan model EOQ dengan kendala nonlinear. Metode penyelesaian model inventori dengan metode aljabar diperkenalkan leh (Luo, \& Chou, 2018). Metode modifikasi fruit fly algorithm diperkenalkan oleh (Mousavi, Alikar, Niaki, \& Bahreininejad, 2015) untuk menyelesaikan permasalahan optimasi alokasi dan inventori. (Rezaeian, Haghayegh, \& Mahdavi, 2016) membahas permasalahan inventori untuk produk yang perishable. (Perlman \& Levner, 2014) menerapkan konsep inventori pada bidang kesehatan.

Penelitian yang telah disebutkan merupakan implementasi konsep inventori deterministik dengan data permintaan dapat dinyatakan dengan pasti. Pada beberapa kasus permintaan tidak dapat dinyatakan dengan pasti, misalnya data permintaan yang diperoleh dari proses peramalan, data permintaan yang tidak sama dan tidak dapat diprediksi pada 
periode berikutnya. Model deterministik tidak tepat digunakan untuk menyelesaikan permasalahan inventori dengan ketidakpastian. Konsep inventori stokastik dapat diterapkan pada permasalahan inventori dengan ketidakpastian. Berikut penelitian terkait permasalahan inventori dengan ketidakpastian. (Azadi at al, 2019) memperkenalkan model inventori stokastik pada permasalahan inventori produk yang mudah ruasak (Perishable). (Qiu, Sun, \& Lim, 2017) memperkenalkan model inventori dengan pendekatan Robust. (Zhang at al, 2018) memperkenalkan model inventori probabilistik. ( $\mathrm{Li} \& \mathrm{Fu}, 2017)$ membahas manajemen inventori menggunakan pendekatan Robust. Pada (Canyakmaz, Ozekici, \& Karaesmen, 2019) dibahas permasalahan inventori stokastik dengan permintaan bergantung pada harga. Penelitian sebelumnya membahas permasalahan inventori stokastik dengan mempertimbangkan ketidakpastian permintaan ataupun ketidakpastian waktu tunggu (lead time). Ketidakpastian permintaan dan waktu tunggu dibahas oleh (Rahdar, Wang, \& Hu, 2018) dengan memperkenalkan model TriLevel Optimization dan model stokastik. Berikut diberikan model stokastik yang diperkenalkan oleh (Rahdar, Wang, \& Hu, 2018).

$$
\begin{aligned}
& \min \zeta=c \mu q_{1}+f v_{1}+h I_{1}+p g_{1}+ \\
& \mathbf{E}\left[c \mu \sum_{t=2}^{T} q_{t}^{s}+f \sum_{t=2}^{T} v_{t}^{s}+h \sum_{t=2}^{T} I_{t}^{S}+\right. \\
& \left.p \sum_{t=2}^{T} g_{t}^{S}\right] \\
& \text { Kendala } \\
& I_{1}=I_{0}+\sum_{k=1-K}^{0} \mu q_{k} \hat{\delta}_{k, 1}+g_{1}-\hat{d}_{1} \\
& q_{1} \leq M v_{1} \\
& I_{t}^{s}=I_{0}+\sum_{k=1-K}^{t-1} \mu q_{k}^{s} \hat{\delta}_{k, t}^{s}+g_{t}^{S}-\sum_{i=1}^{t} \hat{d}_{i}^{s}, \\
& t \in\{2,3, \ldots, T\}, \forall s \\
& q_{t}^{S} \leq M v_{t}^{S}, t \in\{2,3, \ldots, T\}, \forall s \\
& q_{1}, I_{1}, g_{1} \in \mathbb{Z}^{+} ; v_{1} \in\{0,1\}, t \in\{2,3, \ldots, T\}, \\
& \forall s ; q_{t}^{S}, I_{t}^{S}, g_{t}^{S} \in \mathbb{Z}^{+} ; v_{t}^{s} \in\{0,1\}
\end{aligned}
$$

\section{Keterangan}

$q_{1} \in \mathbb{Z}^{+}$

Banyak kelapa yang dipesan pada periode 1

$I_{1} \in \mathbb{Z}^{+} \quad$ Tingkat persediaan periode 1

$g_{1} \in \mathbb{Z}^{+} \quad$ Jumlah kekurangan periode 1

$v_{1} \in\{0,1\} \quad$ Menunjukkan apakah pesanan ditempatkan dalam periode 1 $\left(v_{1}=1\right)$ jika tidak $\left(v_{1}=0\right)$.

$q_{t} \in \mathbb{Z}^{+} \quad$ Banyaknya pemesanan pada periode $\mathrm{t}, \forall t \in\{2,3, \ldots, T\}$

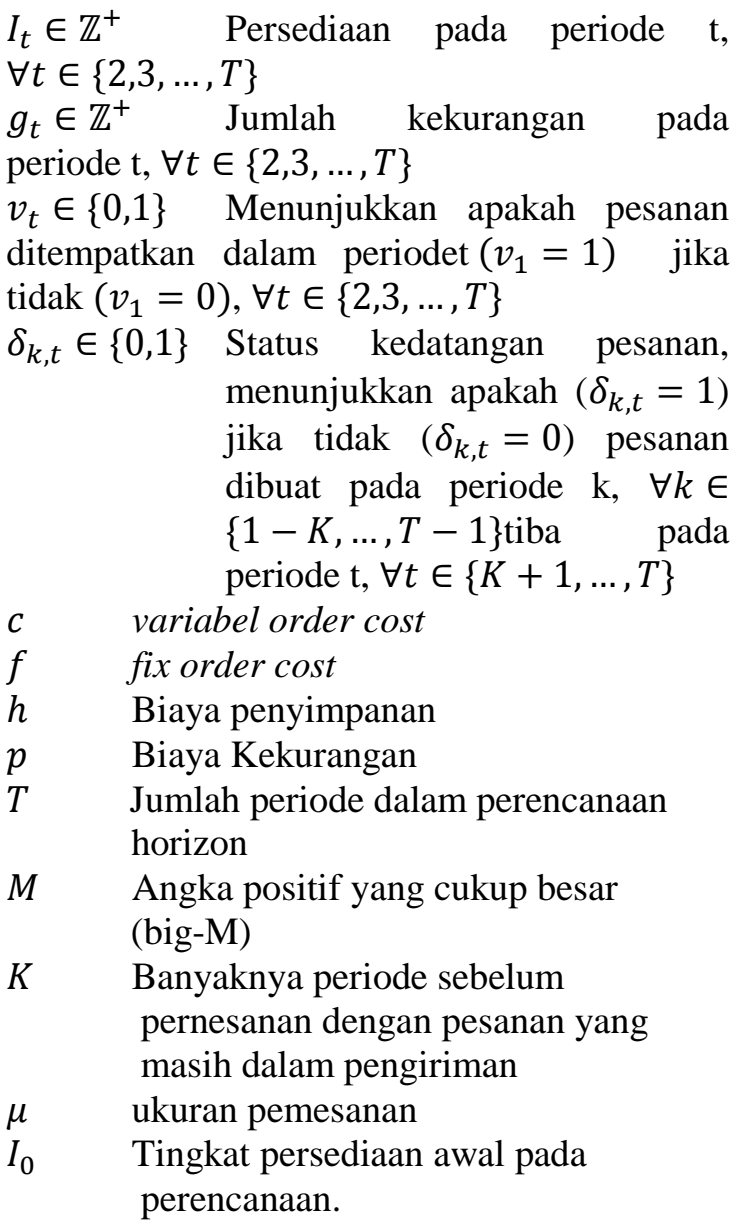

Penelitian ini bertujuan untuk mengetahui distribusi peluang dari data permintaan, total biaya persediaan dan persediaan kelapa optimal di tingkat distributor yang berlokasi di kota Palembang selama dua periode pemesanan menggunakan model persediaan stokastik yang diperkenalkan oleh (Rahdar, Wang, \& Hu, 2018). pada permasalahan optimasi persediaan kelapa. Terdapat ketidakpastian permintaan pelanggan dan waktu tunggu kelapa sampai pada distributor sehingga model stokastik dapat digunakan pada optimasi persediaan.

\section{METODE PENELITIAN}

Berikut diberikan langkah penyelesaian masalah optimasi persediaan kelapa di tingkat distributor.

1. Pengumpulan dan Deskripsi data.

Data yang digunakan pada penelitian ini adalah data primer yang terdiri dari data ukuran pemesanan, persediaan di awal periode, biaya penyimpanan, data biaya tetap pemesanan, biaya kekurangan dan parameter lain yang diberikan pada model Stokastik. Data yang digunakan adalah data dengan dua periode pencatatan, 
masing-masing periode terdiri dari tujuh hari pencatatan.

2. Menentukan nilai-nilai parameter yang digunakan untuk menyusun model stokastik.

3. Menentukan distribusi peluang untuk variabel acak permintaan. Pencocokan kurva menggunakan software Easyfit.

4. Menentukan banyak skenario berdasarkan nilai realisasi variabel acak permintaan.

5. Menyusun model stokastik untuk permasalahan optimasi persediaan kelapa menggunakan model stokastik yang diperkenalkan oleh (Rahdar, Wang, \& $\mathrm{Hu}, 2018$ ) dengan $T=1,2$.

\section{HASIL DAN PEMBAHASAN}

Permasalahan yang dibahas pada makalah ini adalah bagaimana menentukan jumlah persediaan optimal yang meminimumkan total biaya sistem menggunakan model stokastik. Biaya sistem terdiri dari biaya persediaan, biaya pemesanan, biaya penyimpanan dan biaya kekurangan. Berikut diberikan data permintaan dan nilai parameter yang digunakan dalam penyusunan model.

$c=1.500 ; f=2.000 ; h=476 ; p=0$;

$T=2 ; M=100.000 ; K=1 ; \mu=1 \quad$;

$I_{0}=18.618 ; q_{0}=26.000$

$\hat{d}_{1}$ : Permintaan pada periode $1 d_{1}=18587$;

$d_{2}=26010 ; \quad d_{3}=7798 ; \quad d_{4}=22495 ;$

$d_{5}=39804 ; d_{6}=0 ; d_{7}=32532$

$\hat{d}_{2}$ : Permintaan pada periode 2

$d_{1}=20217 ; d_{2}=19005 ; d_{3}=0 ; d_{4}=$ $44970 ; d_{5}=7328 ; d_{6}=18432 ; d_{7}=$ 19998.

Dilakukan pencocokan kurva distribusi untuk variabel acak permintaan pada setiap periode menggunakan software easyfit. Diketahui bahwa data permintaan kelapa berdistribusi seragam diskret. Berdasarkan nilai realisasi peluang variabel acak permintaan dapat dibentuk 49 skenario. Model stokastik (1) ditransformasi ke bentuk deterministik berdasarkan nilai realisasi variabel acak. Diperoleh model matematika sebagai berikut.

$\min Z=(1500)(1) q_{1}+(2000)+$ $(476) I_{1}+(0) g_{1}+$

$\sum_{s=1}^{49}\left[\mathrm{P}_{q}^{s} c \mu \sum_{t=2}^{2} q_{t}^{s}+\mathrm{P}_{v}^{s} f \sum_{t=2}^{2} v_{t}^{s}+\right.$ $\left.\mathrm{P}_{I}^{S} h \sum_{t=2}^{2} I_{t}^{S}+\mathrm{P}_{g}^{S} p \sum_{t=2}^{2} g_{t}^{S}\right]$
Dengan kendala

$I_{1}=18618+\sum_{k=0}^{0}(1)(26000) \hat{\delta}_{0,1}+g_{1}-$
18587
$q_{1} \leq(100000) ;$

$I_{2}^{1}=18618+(1)(26000) q_{1}^{1}+g_{2}^{1}-$

$(18587+20217)$

$I_{2}^{2}=18618+(1)(26000) q_{1}^{2}+g_{2}^{2}-$ $(18587+19005)$

$I_{2}^{3}=18618+(1)(26000) q_{1}^{3}+g_{2}^{3}-$ $(18587+0)$

$I_{2}^{4}=18618+(1)(26000) q_{1}^{4}+g_{2}^{4}-$ $(18587+44970)$

$I_{2}^{5}=18618+(1)(26000) q_{1}^{5}+g_{2}^{5}-$

$(18587+7328)$

$I_{2}^{6}=18618+(1)(26000) q_{1}^{6}+g_{2}^{6}-$

$(18587+18432)$

$I_{2}^{7}=18618+(1)(26000) q_{1}^{7}+g_{2}^{7}-$ $(18587+19998)$

$I_{2}^{8}=18618+(1)(26000) q_{1}^{8}+g_{2}^{8}-$

$(26010+20217)$

$I_{2}^{9}=18618+(1)(26000) q_{1}^{9}+g_{2}^{9}-$

$(26010+19005)$

$I_{2}^{10}=18618+(1)(26000) q_{1}^{10}+g_{2}^{10}-$ $(26010+0)$

$I_{2}^{11}=18618+(1)(26000) q_{1}^{11}+g_{2}^{11}-$ $(26010+44970)$

$I_{2}^{12}=18618+(1)(26000) q_{1}^{12}+g_{2}^{12}-$ $(26010+7328)$

$I_{2}^{13}=18618+(1)(26000) q_{1}^{13}+g_{2}^{13}-$ $(26010+18432)$

$I_{2}^{14}=18618+(1)(26000) q_{1}^{14}+g_{2}^{14}-$ $(26010+19998)$

$I_{2}^{15}=18618+(1)(26000) q_{1}^{15}+g_{2}^{15}-$ $(7798+20217)$

$I_{2}^{16}=18618+(1)(26000) q_{1}^{16}+g_{2}^{16}-$ $(7798+19005)$

$I_{2}^{17}=18618+(1)(26000) q_{1}^{17}+g_{2}^{17}-$ $(7798+0)$

$I_{2}^{18}=18618+(1)(26000) q_{1}^{18}+g_{2}^{18}-$ $(7798+44970)$

$I_{2}^{19}=18618+(1)(26000) q_{1}^{19}+g_{2}^{19}-$ $(7798+7328)$

$I_{2}^{20}=18618+(1)(26000) q_{1}^{20}+g_{2}^{20}-$ $(7798+18432)$

$I_{2}^{21}=18618+(1)(26000) q_{1}^{21}+g_{2}^{21}-$ $(7798+19998)$

$I_{2}^{22}=18618+(1)(26000) q_{1}^{22}+g_{2}^{22}-$ $(22495+20217)$

$I_{2}^{23}=18618+(1)(26000) q_{1}^{23}+g_{2}^{23}-$ $(22495+19005)$

$I_{2}^{24}=18618+(1)(26000) q_{1}^{24}+g_{2}^{24}-$ $(22495+0)$

$I_{2}^{25}=18618+(1)(26000) q_{1}^{25}+g_{2}^{25}-$

$(22495+44970)$ 
$I_{2}^{26}=18618+(1)(26000) q_{1}^{26}+g_{2}^{26}-$ $(22495+7328)$

$I_{2}^{27}=18618+(1)(26000) q_{1}^{27}+g_{2}^{27}-$ $(22495+18432)$

$I_{2}^{28}=18618+(1)(26000) q_{1}^{28}+g_{2}^{28}-$ $(22495+19998)$

$I_{2}^{29}=18618+(1)(26000) q_{1}^{29}+g_{2}^{29}-$ $(39804+20217)$

$I_{2}^{30}=18618+(1)(26000) q_{1}^{30}+g_{2}^{30}-$ $(39804+19005)$

$I_{2}^{31}=18618+(1)(26000) q_{1}^{31}+g_{2}^{31}-$ $(39804+0)$

$I_{2}^{32}=18618+(1)(26000) q_{1}^{32}+g_{2}^{32}-$ $(39804+44970)$

$I_{2}^{33}=18618+(1)(26000) q_{1}^{33}+g_{2}^{33}-$ $(39804+7328)$

$I_{2}^{34}=18618+(1)(26000) q_{1}^{34}+g_{2}^{34}-$ $(39804+18432)$

$I_{2}^{35}=18618+(1)(26000) q_{1}^{35}+g_{2}^{35}-$ $(39804+19998)$

$I_{2}^{36}=18618+(1)(26000) q_{1}^{36}+g_{2}^{36}-$ $(0+20217)$

$I_{2}^{37}=18618+(1)(26000) q_{1}^{37}+g_{2}^{37}-$ $(0+19005)$

$I_{2}^{38}=18618+(1)(26000) q_{1}^{38}+g_{2}^{38}-$ $(0+0)$

$I_{2}^{39}=18618+(1)(26000) q_{1}^{39}+g_{2}^{39}-$ $(0+44970)$

$I_{2}^{40}=18618+(1)(26000) q_{1}^{40}+g_{2}^{40}-$ $(0+7328)$

$I_{2}^{41}=18618+(1)(26000) q_{1}^{41}+g_{2}^{41}-$ $(0+18432)$

$I_{2}^{42}=18618+(1)(26000) q_{1}^{42}+g_{2}^{42}-$ $(0+19998)$

$I_{2}^{43}=18618+(1)(26000) q_{1}^{43}+g_{2}^{43}-$ $(32532+20217)$

$I_{2}^{44}=18618+(1)(26000) q_{1}^{44}+g_{2}^{44}-$ $(32532+19005)$

$I_{2}^{45}=18618+(1)(26000) q_{1}^{45}+g_{2}^{45}-$ $(32532+0)$

$I_{2}^{46}=18618+(1)(26000) q_{1}^{46}+g_{2}^{46}-$ $(32532+44970)$

$I_{2}^{47}=18618+(1)(26000) q_{1}^{47}+g_{2}^{47}-$ $(32532+7328)$

$I_{2}^{48}=18618+(1)(26000) q_{1}^{48}+g_{2}^{48}-$ $(32532+18432)$

$I_{2}^{49}=18618+(1)(26000) q_{1}^{49}+g_{2}^{49}-$ $(32532+19998)$

$q_{2}^{1} \leq 100000 v_{2}^{1}$;

$q_{2}^{3} \leq 100000 v_{2}^{3}$;

$q_{2}^{5} \leq 100000 v_{2}^{5}$ $q_{2}^{6} \leq 100000 v_{2}^{6} ;$

$q_{2}^{8} \leq 100000 v_{2}^{8}$;

$q_{2}^{10} \leq 100000 v_{2}^{10}$

$q_{2}^{11} \leq 100000 v_{2}^{11}$;

$q_{2}^{13} \leq 100000 v_{2}^{13}$;

$q_{2}^{15} \leq 100000 v_{2}^{15}$

$q_{2}^{16} \leq 100000 v_{2}^{16}$;

$q_{2}^{18} \leq 100000 v_{2}^{18}$;

$q_{2}^{20} \leq 100000 v_{2}^{20}$

$q_{2}^{21} \leq 100000 v_{2}^{21}$;

$q_{2}^{23} \leq 100000 v_{2}^{23}$;

$q_{2}^{25} \leq 100000 v_{2}^{25}$

$q_{2}^{26} \leq 100000 v_{2}^{26}$;

$q_{2}^{28} \leq 100000 v_{2}^{28}$;

$q_{2}^{30} \leq 100000 v_{2}^{30}$

$q_{2}^{31} \leq 100000 v_{2}^{31}$;

$q_{2}^{33} \leq 100000 v_{2}^{33}$;

$q_{2}^{35} \leq 100000 v_{2}^{35}$

$q_{2}^{36} \leq 100000 v_{2}^{36}$;

$q_{2}^{38} \leq 100000 v_{2}^{38}$;

$q_{2}^{40} \leq 100000 v_{2}^{40}$;

$q_{2}^{42} \leq 100000 v_{2}^{42}$

$q_{2}^{44} \leq 100000 v_{2}^{44}$

$q_{2}^{46} \leq 100000 v_{2}^{46}$;

$q_{2}^{48} \leq 100000 v_{2}^{48}$;

$q_{1}, g_{1}, g_{1} \in \mathbb{Z}^{+}, v_{1} \in\{0,1\} ; q_{t}, q_{t}, g_{t} \in \mathbb{Z}^{+}$

$q_{2}^{7} \leq 100000 v_{2}^{7}$

$q_{2}^{9} \leq 100000 v_{2}^{9}$;

$q_{2}^{12} \leq 100000 v_{2}^{12}$;

$q_{2}^{14} \leq 100000 v_{2}^{14}$;

$q_{2}^{17} \leq 100000 v_{2}^{17}$;

$q_{2}^{19} \leq 100000 v_{2}^{19}$;

$q_{2}^{22} \leq 100000 v_{2}^{22}$;

$q_{2}^{24} \leq 100000 v_{2}^{24}$;

$q_{2}^{27} \leq 100000 v_{2}^{27}$

$q_{2}^{29} \leq 100000 v_{2}^{29}$;

$q_{2}^{32} \leq 100000 v_{2}^{32}$;

$q_{2}^{34} \leq 100000 v_{2}^{34}$;

$q_{2}^{37} \leq 100000 v_{2}^{37}$;

$q_{2}^{39} \leq 100000 v_{2}^{39}$;

$q_{2}^{41} \leq 100000 v_{2}^{41}$;

$q_{2}^{43} \leq 100000 v_{2}^{43}$;

$q_{2}^{45} \leq 100000 v_{2}^{45}$;

$q_{2}^{47} \leq 100000 v_{2}^{47}$;

$q_{2}^{49} \leq 100000 v_{2}^{49}$

Model (2) diselesaikan dengan software Lingo 13.0, diperoleh solusi optimal sebagai berikut.

$Z=45.672 .910$;

$I_{1}=26031 ; g_{1}=q_{1}=0 ; I_{2}^{1}=5814 ;$

$I_{2}^{2}=7026 ; \quad q_{2}^{s}=0,1,2, \cdots, 49 ;$

$I_{2}^{3}=26031 ; \quad I_{2}^{5}=18703 ; \quad I_{2}^{6}=7599 ;$

$I_{2}^{7}=6033 ; \quad I_{2}^{10}=18608 ;$

$I_{2}^{12}=11280 ; \quad I_{2}^{13}=176$;

$I_{2}^{15}=16603 ; I_{2}^{16}=17815$;

$I_{2}^{17}=36820 ; \quad I_{2}^{19}=29492 ;$

$I_{2}^{20}=18388 ; \quad I_{2}^{21}=16822 ;$

$I_{2}^{22}=1916 ; \quad I_{2}^{23}=3128$;

$I_{2}^{24}=22133 ; \quad I_{2}^{26}=14805$;

$I_{2}^{27}=3701 ; I_{2}^{28}=2135 ;$

$I_{2}^{31}=4814 ; \quad I_{2}^{36}=24401 ;$

$I_{2}^{37}=25613 ; \quad I_{2}^{38}=44618 ;$

$I_{2}^{40}=37290 ; \quad I_{2}^{41}=26186 ;$

$I_{2}^{42}=24620 ; \quad I_{2}^{45}=12086 ; \quad I_{2}^{47}=4758 ;$

$I_{2}^{4}=I_{2}^{8}=I_{2}^{9}=I_{2}^{11}=I_{2}^{14}=I_{2}^{18}=$

$I_{2}^{25}=I_{2}^{29}=I_{2}^{30}=I_{2}^{32}=I_{2}^{33}=I_{2}^{34}=$

$I_{2}^{35}=I_{2}^{39}=I_{2}^{43}=I_{2}^{44}=I_{2}^{46}=I_{2}^{48}=$

$I_{2}^{49}=0 ; v_{2}^{s}=0 ; s=1,2, \cdots, 49$ 
Penyelesaian model (2) menggunakansoftware Lingo 13.0 diperoleh total biaya yang terdiri dari biaya pemesanan, biaya penyimpanan dan biaya kekurangan yaitu sebesar Rp.45.672.910. Pada periode 1 diperoleh tingkat persediaan sebesar 26031 butir kelapa dan tidak dilakukan pemesanan. Kemungkinan tingkat persediaan pada periode 2 adalah 5814; 7026; 26031; 18703; 7599; 6033; $18608 ; 11280 ; 176 ; 16603 ; 17815 ; 36820$; 29492; 18388; 16822; 1916; 3128; 22133; 4805; 3701; 2135; 4814; 24401; 25613; 44618; 37290; 26186; 24620; 12086; 4758. Nilai $v_{2}^{s}$ adalah nol, hal ini berarti pada periode dua tidak dilakukan pemesanan.

\section{KESIMPULAN DAN SARAN}

Berdasarkan uraian hasil dan pembahasan yang diperoleh berikut diberikan kesimpulan dan saran.

\section{A. Kesimpulan}

Berdasarkan data yang diperoleh dan pembahasan pada permasalahan optimasi persediaan kelapa di tingkat distributor dapat disimpulkan bahwa :

1. Data permintaan kelapa mengikuti distribusi seragam diskret

2. Total biaya persediaan kelapa selama dua periode perencanaan sebesar Rp. 45.672.910 dengan 49 skenario

3. Persediaan optimal periode satu sebesar 26031 butir, persediaan optimal untuk periode dua dilihat berdasarkan nilai skenario yang muncul yaitu $I_{2}^{1}=5814 ; I_{2}^{2}=7026$; $I_{2}^{3}=26031 ; I_{2}^{5}=18703 ; I_{2}^{6}=7599 ;$ $I_{2}^{7}=6033 ; \quad I_{2}^{10}=18608 ; \quad I_{2}^{12}=$ $11280 ; \quad I_{2}^{13}=11280 ; \quad I_{2}^{15}=16603$; $I_{2}^{16}=17815 ; \quad I_{2}^{17}=36280 ; ;$ $I_{2}^{19}=29492 ; \quad I_{2}^{20}=18388 ;$ $I_{2}^{21}=16822 ; \quad I_{2}^{22}=1916$; $I_{2}^{23}=3128 ; \quad I_{2}^{24}=22133 ; ;$ $I_{2}^{26}=14805 ; I_{2}^{27}=3701 ;$

$I_{2}^{28}=2135 ; \quad I_{2}^{31}=4814 ; \quad I_{2}^{36}=$ $24401 ; \quad I_{2}^{37}=25613 ; \quad I_{2}^{38}=44618$; $I_{2}^{40}=37290 ; \quad I_{2}^{41}=26186 ; \quad ;$ $I_{2}^{42}=24620 ; \quad I_{2}^{45}=12086 ;$ $I_{2}^{47}=4758$;

\section{B. Saran}

Nilai optimal yang diperoleh dipengaruhi oleh banyaknya skenario yang ditentukan. Pada makalah ini ditentukan sebanyak 49 skenario berdasarkan nilai realisasi variabel acak permintaan. Data permintaan yang digunakan untuk setiap periodenya sama yaitu 7 hari dan data permintaan berdistribusi seragam, untuk penelitian selanjutnya dapat diterapkan pada data dengan jumlah data pada setiap periodenya berbeda.

\section{DAFTAR PUSTAKA}

Azadi, Z., Eksioglu, S. D., Eksioglu, B., \& Palak, G. (2019). Stochastic Optimization Models for Joint Pricing and Inventory Replenishment of Perishable Products. Computers \& Industrial Engineering, 127 (January),625-642. https://doi.org/10.1016/j.cie.2018.11.004

Canyakmaz, C., Özekici, S., \& Karaesmen, F. (2019). An inventory model where customer demand is dependent on a stochastic price process. International Journal of Production Economics, 212, 139-152.

https://doi.org/10.1016/j.ijpe.2019.01.039

Cárdenas-barrón, L. E., Shaikh, A. A., Tiwari, S., \& Treviño-garza, G. (2018). An EOQ inventory model with nonlinear stock dependent holding cost, nonlinear stock dependent demand and trade credit. Computers \& Industrial Engineering. https://doi.org/10.1016/j.cie.2018.12.004

Li, Z., \& Fu, Q. G. (2017). Robust Inventory Management with Stock-out Substitution. International Journal of Production Economics,193,813-826. https://doi.org/10.1016/j.ijpe.2017.09.011

Luo, X., \& Chou, C. (2018). International Journal of Production Economics Technical note : Solving inventory models by algebraic method. International Journal of Production Economics, 200(March),130-133.

https://doi.org/10.1016/j.ijpe.2018.03.023 
Mousavi, S. M., Alikar, N., Niaki, S. T. ., \& Bahreininejad, A. (2015). Optimizing a location allocation-inventory problem in a two-echelon supply chain network : A modified Fruit Fly optimization algorithm. Computers \& Industrial Engineering, 87, 543-560.

https://doi.org/10.1016/j.cie.2015.05.022

Perlman, Y., \& Levner, I. (2014). Perishable Inventory Management in Healthcare. Journal of Service and Management, 2014(February), 11-17.

Qiu, R., Sun, M., \& Lim, Y. F. (2017). Optimizing (s, S) Policies for Multi-period Inventory Models with Demand Distribution Uncertainty: Robust Dynamic Programming Approaches. European Journal of Operational Research, 261, 880-892.

https://doi.org/10.1016/j.ejor.2017.02.027

Rahdar, M., Wang, L., \& Hu, G. (2018). A trilevel optimization model for inventory control with uncertain demand and lead time. International Journal of Production Economics,195,96-105.

https://doi.org/10.1016/j.ijpe.2017.10.011

Rezaeian, J., Haghayegh, S., \& Mahdavi, I. (2016). Designing an Integrated Production / Distribution and Inventory Planning Model of Fixed-life Perishable Products. Journal of Otimization in Industrial Engineering, 19, 47-59.

Sanni, S., \& Neill, B. O. (2019). Computers \& Industrial Engineering Inventory optimisation in a three-parameter Weibull model under a prepayment system. Computers \& Industrial Engineering, 128(December 2018), 298-304. https://doi.org/10.1016/j.cie.2018.12.045

Zhang, Y., Hua, G., Wang, S., Zhang, J., \& Fernandez, V. (2018). Managing Demand Uncertainty: Probabilistic Selling Versus Inventory Substitution. International Journal of Production Economics, 196, 56-67.

https://doi.org/10.1016/j.ijpe.2017.10.001

Zheng, X., Yin, M., \& Zhang, Y. (2019). Integrated Optimization of Location, Inventory and Routing In Supply Chain Network Design. Transportation Research Part B, 121, 1-20. https://doi.org/10.1016/j.trb.2019.01.003 